\title{
Improving patient outcomes following glaucoma surgery: state of the art and future perspectives
}

\author{
This article was published in the following Dove Press journal: \\ Clinical Ophthalmology \\ 2 May 2014 \\ Number of times this article has been viewed
}

\author{
Tine Van Bergen' \\ Sarah Van de Velde' \\ Evelien Vandewalle ${ }^{3}$ \\ Lieve Moons ${ }^{2}$ \\ Ingeborg Stalmans ${ }^{1,3}$ \\ 'Laboratory of Ophthalmology, \\ $\mathrm{KU}$ Leuven, ${ }^{2}$ Unit Animal Physiology \\ and Neurobiology, KU Leuven, \\ ${ }^{3}$ Department of Ophthalmology, \\ University Hospitals Leuven, \\ Leuven, Belgium
}

\begin{abstract}
Of all the treatments currently used to lower intraocular pressure in glaucoma patients, filtration surgery is known to be the most effective. However, in a significant percentage of cases, the constructed channel closes due to excessive scar formation, resulting in surgical failure. The process of postoperative wound healing is characterized by the coagulative and inflammatory phase, followed by the proliferative and repair phase, and finally the remodeling phase. Perioperative antimitotic agents, such as mitomycin $\mathrm{C}$ and 5-fluorouracil, are known to modulate the process of wound healing and to improve surgical outcome, but they carry a risk of vision-threatening complications. New alternative strategies to prevent filtration failure, such as inhibition of transforming growth factor- $\beta$, vascular endothelial growth factor, and placental growth factor, have shown promising results in the improvement of surgical success. However, it remains necessary to broaden the therapeutic approach by focusing on combined therapies and on extended drug delivery.
\end{abstract}

Keywords: glaucoma filtration surgery, filtration failure, wound healing, wound modulating agents

\section{Introduction}

The most effective treatment to lower intraocular pressure (IOP) in glaucoma patients is glaucoma filtration surgery. Trabeculectomy, the reference procedure, is a surgical technique by which a tunnel is created between the anterior chamber and the subconjunctival space, with removal of a part of the trabecular meshwork. A controlled leaking area for aqueous humor is formed, called a filtration bleb. Although this procedure may be crucial in the management of glaucoma, ${ }^{1,2}$ it carries a risk of complications. Excessive postoperative wound healing of the conjunctiva and Tenon's capsule, with subsequent scarring, is known to frequently lead to surgical failure, ${ }^{3}$ associated with poor postoperative IOP control and consequent progression of glaucomatous disc cupping and visual field loss.

Pharmacological enhancement of trabeculectomy using different antiscarring agents was found to significantly improve surgical success rates. Indeed, the use of 5-fluorouracil and mitomycin C, known as the gold standards in clinical practice, has improved the success rate significantly by enhancing bleb survival. However, long-term success rates for blebs supplemented with these antimitotics were not as promising as desired. Moreover, the nonspecific mechanism of action of these agents may result in severe vision-threatening side effects, such as corneal toxicity, thin-walled avascular blebs, blebitis, endophthalmitis, and hypotony. Therefore, there is still a need for alternative strategies to prevent filtration failure. In this review, an overview of the current wound healing modulation agents is provided, and new approaches to wound modulation that may improve glaucoma filtration surgery are discussed.
Correspondence: Ingeborg Stalmans University Hospitals Leuven, Department of Ophthalmology, Kapucijnenvoer 33, B-3000, Leuven, Belgium

Tel +3216332372

Fax +3216332367

Email ingeborg.stalmans@uzleuven.be 


\section{Process of wound healing}

Wound healing comprises a cascade of different processes that are closely linked, and includes a coagulative and inflammatory phase, followed by a proliferation and repair phase, and finally a remodeling phase. ${ }^{4}$ Figure 1 gives a schematic overview of the wound healing process and the various molecules (growth factors, cytokines, and proteinases) involved in the different phases. After injury, leakage of plasma proteins (fibrinogen, fibronectin, and plasminogen) and blood cells (red and white blood cells and platelets) from disrupted blood vessels takes place. Clotting factor activation leads to conversion of fibrinogen to fibrin, to reduce blood loss. Clots as well as hormones (histamine, serotonin, prostaglandins and leukotrienes), cytokines (eg, interleukin-1 and interferon$\alpha 2 b$ ) and growth factors (eg, vascular endothelial growth factor [VEGF], placental growth factor, platelet-derived growth factor, fibroblast growth factor, and transforming growth factor $[\mathrm{TGF}]-\beta)$, released during vascular injury, lead to cellular migration and attraction of neutrophils, macrophages, and lymphocytes to the damaged tissue during the inflammatory phase. This results in a proliferative and repair phase during which endothelial cells and fibroblasts migrate into the site of injury. In this phase, angiogenesis and formation of granulation tissue occurs. Finally, remodeling of tissue takes place and involves the formation of scar tissue. Blood vessels regress over time, and fibroblasts induce crosslinking of collagen type I and elastin, which leads to collagen supercoil formation and dense scar tissue. ${ }^{4,5}$ After trabeculectomy, wound healing under the scleral flap may play a role in some cases, but Tenon fibroblasts are regarded as the key players in the initiation of wound healing and fibrotic scar formation. ${ }^{6}$ Although it is known that bleb failure in humans normally happens at around 2-3 months, ${ }^{7,8}$ proliferation of subconjunctival fibroblasts already occurs on postoperative days 3-5. ${ }^{9}$ The further development of conjunctival fibrosis, regulated by the release of a number of cytokines and growth factors, appears as a result of inflammation, angiogenesis, progressive fibroblast proliferation and migration, and collagen deposition at the site of filtration. ${ }^{4}$

\section{Modulators of wound healing in clinical practice}

Gentle handling of tissue and control of intraoperative bleeding lead to reduced fibroblast activity, but such preventive maneuvers are usually insufficient to prevent scarring in the long term. ${ }^{4}$ Therefore, various anti-inflammatory and antiproliferative agents are used in clinical practice to inhibit wound healing and to improve bleb survival.

\section{Anti-inflammatory agents}

Inhibition of inflammation and wound healing by corticosteroids is largely mediated by suppression of leukocyte concentration and function, as well as by their effects on vascular permeability. This leads to less local tissue disruption, reduced mitogen and growth factor release, and less clot and fibrin production, resulting in diminished fibroblast activity and wound healing. ${ }^{4}$ Corticosteroids are therefore frequently used as anti-inflammatory agents after

\section{Coagulative phase}

\section{Proliferation and repair phase}

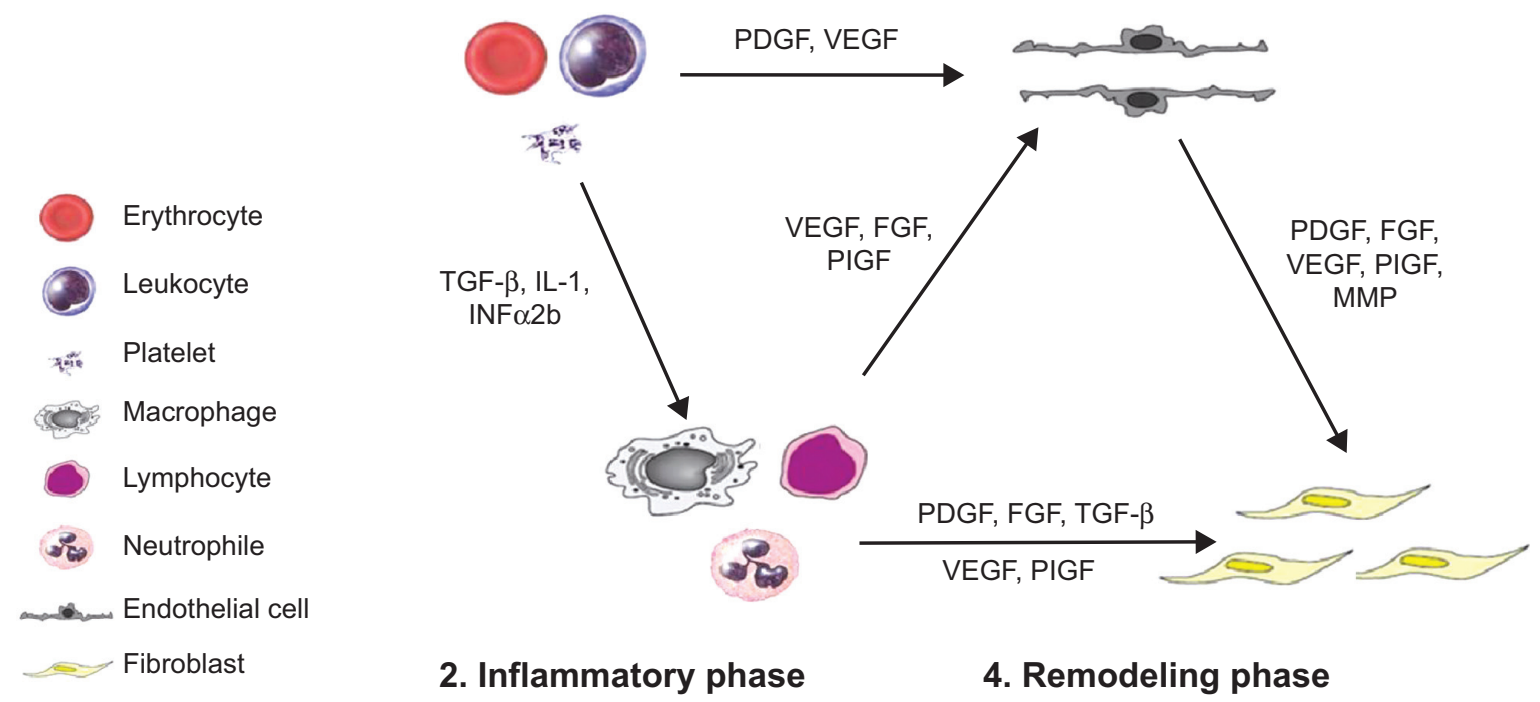

Figure I Schematic overview of the process of wound healing and the most important molecules (growth factors, cytokines, and proteinases) involved. Abbreviations: FGF, fibroblast growth factor; IL, interleukin; MMP, matrix metalloproteinase; PDGF, platelet-derived growth factor; PIGF, placental growth factor; TGF- $\beta$, transforming growth factor beta; VEGF, vascular endothelial growth factor; INF $\alpha 2 b$, interferon alpha $2 b$. 
glaucoma filtration surgery. Theoretically, they carry a risk of inducing a steroid response, resulting in elevated IOP. It is known that approximately $18 \%-36 \%$ of the general population is steroid-responsive, but this prevalence can increase to $46 \%-92 \%$ in patients with primary-open angle glaucoma. ${ }^{10}$ It is clear that steroid-induced ocular hypertension is associated with specific morphological changes in the trabecular meshwork, such as an increased deposition of extracellular matrix and altered trabecular meshwork cell function, which in turn will cause disturbed aqueous humor outflow and an increase in IOP. ${ }^{11}$ Although these morphological changes in the trabecular meshwork still exist after glaucoma filtration surgery, it is known that steroid response is less common after surgery, presumably because the aqueous humor bypasses the trabecular meshwork via the created channel. Indeed, it has been shown that aqueous flow after surgery is reduced through the trabecular pathway, and that after a successful trabeculectomy, the diameter of Schlemm's canal decreases, most likely due to underperfusion of the trabecular meshwork..$^{12,13}$ This may explain why only $17 \%-36 \%$ of operated glaucoma patients develop a steroid-induced rise in IOP after trabeculectomy, ${ }^{14}$ whereas the risk in nonoperated glaucoma patients is much higher $(46 \%-92 \%) .{ }^{10}$ Moreover, a ten-year follow-up of a prospective randomized trial of postoperative corticosteroids after trabeculectomy showed that IOP was stabilized in $82.8 \%$ ( 38 of 46 eyes) of steroidtreated eyes after successful glaucoma surgery. ${ }^{15}$ Finally, it has been suggested that the risk of a steroid response might increase after filtration failure, since the aqueous humor must again flow through the altered trabecular meshwork. ${ }^{16}$ Also, nonsteroidal anti-inflammatory drugs suppress the inflammatory response in the process of wound healing, but are known to be less potent as compared with corticosteroids. ${ }^{17}$

\section{Antimitotics}

In the early 1980s, antimitotic agents, such as 5-fluorouracil and mitomycin $\mathrm{C}$, were found to be effective in inhibiting activation of fibroblasts. Although these agents have impacted the success rate of glaucoma filtration surgery, they carry a risk of vision-threatening complications. With lower levels of exposure, bleb-related complications are less frequent, but filtration failure is more common, representing a trade-off between efficacy and safety.

\section{5-Fluorouracil}

The antiproliferative effect of 5-fluorouracil (Hoffman-La Roche Ltd., Basel, Switzerland), a chemotherapeutic agent, is mediated by antagonizing pyrimidine metabolism. It interferes with the synthesis of thymidine nucleotides, resulting in inhibition of DNA synthesis and ultimately in cell death. ${ }^{18}$ Khaw et al showed that 5 -fluorouracil is an effective inhibitor of fibroblast growth. A five-minute exposure resulted in arrest of growth and had a long-lasting effect on human Tenon fibroblasts. ${ }^{19}$ Animal studies demonstrated that adjunctive 5-fluorouracil following trabeculectomy resulted in prolonged bleb survival with decreased scarring and fibroblast proliferation compared with no 5 -fluorouracil. ${ }^{20}$ Use of 5 -fluorouracil at high levels, however, frequently leads to corneal toxicity and apoptosis, since 5-fluorouracil is toxic to all actively replicating tissues, such as corneal epithelium. ${ }^{21}$

\section{Mitomycin C}

Mitomycin C (Kyowa Hakko Kirin Co., Ltd., Princeton, NJ, USA), is another chemotherapeutic agent with antiproliferative properties. It undergoes metabolic activation via reduction into an alkylating agent that cross-links DNA. Mitomycin C not only inhibits DNA replication, but also mitosis and synthesis of proteins, since it can interfere with any phase in the cell cycle. ${ }^{4}$ Inhibition of the proliferative phase of the wound healing pathway by mitomycin $\mathrm{C}$ increases the success rate of glaucoma surgery, mainly through inhibition of proliferation of fibroblasts and endothelial cells. ${ }^{22}$ Importantly, different aspects of mitomycin $\mathrm{C}$ administration, including dose and exposure time, can determine the outcome of success and affect the wound healing process. It is indeed known that brief intraoperative application of mitomycin $\mathrm{C}(2-2.5$ minutes) is as effective for improvement of surgical outcome as a long exposure (5 minutes), ${ }^{23,24}$ whereas a low dose of mitomycin $\mathrm{C}$ $(0.002 \%)$ shows reduced effectiveness as compared with a higher dose $(0.02 \%) .{ }^{25}$ In addition to dose and duration of application, the size of the surface area can also affect the surgical outcome. Indeed, a large area treated with mitomycin $\mathrm{C}$ is more effective in achieving and maintaining target IOP, and the incidence of bleb scarring is lower compared with eyes with small areas of application. ${ }^{26-28}$ Moreover, Cordeiro et al reported that diffuse noncystic blebs were observed more often in rabbits treated with large sponges $(8 \times 10 \mathrm{~mm})$ than in those treated with small sponges $(4 \times 2 \mathrm{~mm}) .{ }^{29}$ Khaw et al showed that mitomycin $\mathrm{C}$ is more potent than 5-fluorouracil. ${ }^{30,31}$ They found that fibroblasts cultured from rabbit samples treated with mitomycin C still induced inhibition of growth at one month, while fibroblasts from 5-fluorouracil-treated rabbits demonstrated full recovery from growth arrest after 7 days. This can be explained by their different mode of action, since it is known that mitomycin $\mathrm{C}$ induces permanent apoptosis through activation of caspase-3 and caspase-9, Fas, Bad, and phosphorylated p53 in human Tenon fibroblasts, while this is not the case 
after administration of 5-fluorouracil. ${ }^{32}$ Mitomycin C-related cytological toxicity and apoptosis has been associated with the development of thin-walled avascular blebs, which carry a risk of hypotony and endophthalmitis. ${ }^{33}$ Comparative clinical trials demonstrated that 5-fluorouracil was associated with fewer side effects than mitomycin $\mathrm{C}$, but seemed to be less efficient in improving the surgical outcome. ${ }^{34-36}$

Altogether, although these anti-inflammatory and antimitotic agents were found to be effective in inhibiting the process of wound healing in clinical practice, they are not sufficiently effective to satisfactorily inhibit scarring after filtering surgery, and some carry a risk of severe side effects. Therefore, there is still a need for new approaches in modulation of wound healing to prevent filtration failure.

\section{State of the art in modulation of wound healing}

The aqueous humor flowing through the constructed channel into the bleb after glaucoma surgery contains a large number of growth factors. It is known that the presence of growth factors in the aqueous humor of patients with glaucoma can increase the proliferation of Tenon fibroblasts by $60 \%$ compared with the aqueous humor of normal persons. ${ }^{37}$ As such, pre-existing elevated aqueous levels of these growth factors may put patients with glaucoma at a higher risk of scarring after filtration surgery. Therefore, the upregulated growth factors in the aqueous humor of patients with glaucoma can be considered as potential targets in the development of new wound modulation agents. Indeed, a number of growth factor inhibitors have been investigated to improve the surgical outcome after glaucoma filtration surgery. Table 1 represents an overview of the new wound modulation agents.

\section{Inhibition of TGF- $\beta$}

TGF- $\beta$ is a key cytokine in the process of wound healing and has been found to be present at significantly higher levels in the aqueous humor of patients with glaucoma than in that of normal individuals. ${ }^{38}$ Moreover, TGF- $\beta 2$ is known to stimulate proliferation of human Tenon fibroblasts in vitro and to enhance fibroblast-mediated collagen contraction. ${ }^{39}$ Therefore, the strategy of inhibiting this growth factor has been extensively investigated by a group led by Professor PT Khaw (Moorfields Eye Hospital and UCL Institute of Ophthalmology, London, UK). Blocking TGF- $\beta 2$ with a recombinant human monoclonal antibody (CAT-152, Cambridge Antibody Technology, Cambridge, UK) seemed promising with regard to proliferation of Tenon fibroblasts and in an animal model. Khaw's group investigated CAT-152 as an adjunct to glaucoma filtration surgery in a rabbit model and showed that repeated subconjunctival injections ( $1 \mathrm{mg} / \mathrm{mL}$ on postoperative days $0,1,2,3$, and 7) significantly improved the surgical outcome and bleb survival compared with controls. Histologically, CAT-152-treated eyes showed less collagen deposition and clear evidence of bleb formation, without side effects. ${ }^{40}$ A clinical study was initiated but was terminated prematurely due to lack of efficacy at the dose used $(1 \mathrm{mg} / \mathrm{mL}) .{ }^{41}$ Decorin, a naturally occurring TGF- $\beta$ inhibitor, also significantly altered conjunctival scarring and the surgical outcome of glaucoma filtration surgery in rabbits, but no clinical data are available as yet. ${ }^{42}$ Inhibition of TGF- $\beta 2$ by other agents, such as suramin (Bayer AG, Leverkusen, Germany), ${ }^{43,44}$ tranilast (Kissei Pharmaceutical Co., Ltd., Matsumoto City, Japan), ${ }^{45-47}$ lovastatin (Merck \& Co., Inc., Whitehouse Station, NJ, USA), ${ }^{48}$ and ALK5 inhibitors, ${ }^{49,50}$ has also been attempted in in vitro and animal studies, with promising results. A novel approach for targeting the TGF- $\beta$ signaling pathway, currently under investigation, is the use of microRNA; ${ }^{51}$ however, confirmation in animal studies is required.

\section{Inhibition of VEGF}

VEGF is known to play an important role in scar formation. ${ }^{52}$ Increased concentrations of VEGF have been demonstrated in the aqueous humor from eyes of patients with glaucoma when compared with nonglaucomatous controls. ${ }^{53-55}$ In addition to being a potent inducer of angiogenesis, VEGF promotes the migration of inflammatory cells (such as neutrophils and macrophages) and fibroblasts. This growth factor indirectly stimulates fibrosis via angiogenesis, and also has a direct effect on the activity of fibroblasts. ${ }^{56-58}$ Therefore, VEGF inhibitors were investigated by several groups as a potential antiscarring adjunct to filtration surgery.

Our group showed for the first time in a rabbit model of glaucoma filtration surgery that a single subconjunctival (2.5 mg) and intracameral (5 mg) injection of bevacizumab (Genentech, Inc., San Francisco, CA, USA) was effective in improving the outcome of glaucoma surgery by increasing bleb area and survival. This was associated with a reduction in angiogenesis during the initial phase of healing and with diminished fibrosis in the later stages. ${ }^{53}$ When compared with blebs treated with 5-fluorouracil (5 mg), those treated with the VEGF inhibitor (1.25 mg) survived longer, ${ }^{59}$ and combining bevacizumab $(2.5 \mathrm{mg})$ and 5-fluorouracil $(5 \mathrm{mg})$ resulted in $100 \%$ bleb survival and a greater antifibrotic effect compared with monotherapy using each inhibitor. ${ }^{60}$ Importantly, the various VEGF inhibitors available differ in their isoform selectivity, with implications for both efficacy and safety. 
Table I New wound modulation agents

\begin{tabular}{|c|c|c|c|c|}
\hline Inhibitor & Mechanism of action & Phase of wound healing & Study & Reference \\
\hline CAT-I52 & Antibody against TGF- $\beta 2$ & Inflammation, fibrosis & In vitro (HTF), rabbit, phase III trial & 40,41 \\
\hline Decorin & Inhibition of TGF- $\beta 2$ & Inflammation, fibrosis & Rabbit & 42 \\
\hline Suramin & Inhibition of TGF- $\beta$, PDGF, and FGF & Inflammation, fibrosis & Rabbit, case series & 43,44 \\
\hline Tranilast & Inhibition of TGF- $\beta$, IL-I, and PGE2 & Inflammation, fibrosis & In vitro (RTF), rabbit, pilot study & $45-47$ \\
\hline Lovastatin & Inhibition of Rho pathway of TGF- $\beta$ & Inflammation, fibrosis & In vitro (HTF) & 48 \\
\hline ALK inhibitor & Inhibition of ALK signaling of TGF- $\beta$ & Inflammation, fibrosis & In vitro (RTF), rabbit & 49,50 \\
\hline microRNA & Gene suppression of TGF- $\beta$ & Fibrosis & In vitro (HTF) & 51 \\
\hline Pegaptanib & Aptamer against VEGF ${ }_{165}$ & Angiogenesis & In vitro (HTF and RTF), rabbit & 61 \\
\hline Ranibizumab & Fab fragment against all VEGF isoforms & Angiogenesis, fibrosis & Pilot study & 99 \\
\hline Bevacizumab & Antibody against all VEGF isoforms & Angiogenesis, fibrosis & $\begin{array}{l}\text { In vitro (HTF and RTF), rabbit, } \\
\text { case reports and series, } \\
\text { pilot study, RCT }\end{array}$ & $\begin{array}{l}53,59,60 \\
62-75,97 \\
98,100\end{array}$ \\
\hline 5DIID4 & Antibody against PIGF & $\begin{array}{l}\text { Inflammation, angiogenesis, } \\
\text { fibrosis }\end{array}$ & In vitro (MTF), mouse & 76 \\
\hline Y-27932 & Inhibition of ROCK & Inflammation, fibrosis & In vitro (HTF), rabbit & 93,94 \\
\hline PDT & Phototoxicity of Tenon fibroblasts & Angiogenesis, fibrosis & $\begin{array}{l}\text { In vitro (HTF), rabbit, } \\
\text { pilot study, RCT }\end{array}$ & $101-104$ \\
\hline Saratin & Inhibition of platelet adhesion & Coagulation, fibrosis & Rabbit & 105,106 \\
\hline Sonepcizumab & Antibody against SIP & Fibrosis & Rabbit & 107 \\
\hline Doxycycline & $\begin{array}{l}\text { Inhibition of MMP-I, MMP-2, MMP-8, } \\
\text { MMP-9, MMP-I } 3\end{array}$ & Inflammation, fibrosis & Rabbit & 108 \\
\hline Pirfenidone & Inhibition of TGF- $\beta$, CTGF, PDGF, TNF- $\alpha$ & Inflammation, fibrosis & In vitro (HTF), rabbit & 109,110 \\
\hline Tacrolimus & Immunosuppressive agent & Inflammation, fibrosis & Rabbit & III \\
\hline Octreotide & Octapeptide of somatostatin & Inflammation, fibrosis & Rabbit & III \\
\hline
\end{tabular}

Abbreviations: HTF, human Tenon fibroblasts; RTF, rabbit Tenon fibroblasts; RCT, randomized controlled trial; MTF, murine Tenon fibroblasts; PDT, photodynamic therapy; PIGF, placental growth factor; MMP, matrix metalloproteinase; VEGF, vascular endothelial growth factor; IL, interleukin; PGE2, prostaglandin E2; FGF, fibroblast growth factor; TNF- $\alpha$, tumor necrosis factor alpha; TGF- $\beta$, transforming growth factor beta; PDGF, platelet-derived growth factor; CTGF, connective tissue growth factor; ALK, anaplastic lymphoma kinase; CAT-I52, lerdelimumab; ROCK, Rho-associated protein kinase.

Based on their VEGF isoform targets, two types of VEGF inhibitors have been identified, ie, selective and nonselective. The effect of pegaptanib (Pfizer Inc., New York, NY, USA), a selective $\mathrm{VEGF}_{165}$ inhibitor, on surgical outcome in a rabbit model of glaucoma surgery was less pronounced than that of nonselective VEGF inhibition, due to a retained action of the $\mathrm{VEGF}_{121}$ and $\mathrm{VEGF}_{189}$ isoforms. It is indeed known that Tenon fibroblasts proliferation is mainly induced by these isoforms, while $\mathrm{VEGF}_{165}$ has less pronounced effects on Tenon fibroblasts. ${ }^{61}$

Meanwhile, a number of clinical case reports and case series have also shown a beneficial effect of subconjunctival $(1,1.25$, and $2.5 \mathrm{mg})$ and topical $(5 \mathrm{mg} / \mathrm{mL})$ bevacizumab, a nonselective VEGF inhibitor, in reducing IOP and improving the surgical outcome. ${ }^{62-67}$ These studies also demonstrated that the antibody against VEGF is safe for ocular use. An early pilot study to evaluate a single subconjunctival bevacizumab injection $(1.25 \mathrm{mg})$ demonstrated that this VEGF inhibitor is a potential adjunctive treatment for reducing the incidence of bleb failure after trabeculectomy. Six-month outcomes showed that trabeculectomy was successful in terms of IOP control in eleven of 12 eyes (92\%), with an average IOP reduction of $52 \% .{ }^{68}$ This beneficial effect was confirmed in more recent studies indicating no significant differences between subconjunctival bevacizumab (1.25 and $2.5 \mathrm{mg})$ and mitomycin $\mathrm{C}(0.03 \%$ for 3 minutes $)$ in terms of morphological bleb features and IOP-lowering. ${ }^{69,70}$

On the other hand, four further pilot studies showed that administration of bevacizumab ( 0.2 and $1.25 \mathrm{mg})$ during trabeculectomy did not affect IOP differently from placebo ${ }^{71}$ or 5-fluorouracil (5 and 7.5 mg). ${ }^{72-74}$ Notably, all these studies included small numbers of patients or had a short follow-up duration, meaning that they lacked the necessary power to draw firm conclusions. Therefore, our group at the University Hospitals of Leuven performed a prospective, randomized, double-blind, placebo-controlled trial in which a 12-month follow-up was undertaken in 138 patients, 69 of whom were treated with bevacizumab $(1.25 \mathrm{mg}$ by intracameral injection). The absolute success rate was higher in the bevacizumab group than in the placebo group ( $71 \%$ versus $51 \%$, respectively), with the need for IOP-lowering interventions (needlings) being lower after bevacizumab treatment (12\% versus 33\%). ${ }^{75}$ Figure 2 shows blebs from the bevacizumab and placebo groups at 6 months of follow-up. Bevacizumab-treated eyes showed less vascularity than those treated with placebo. These recent insights open up promising 

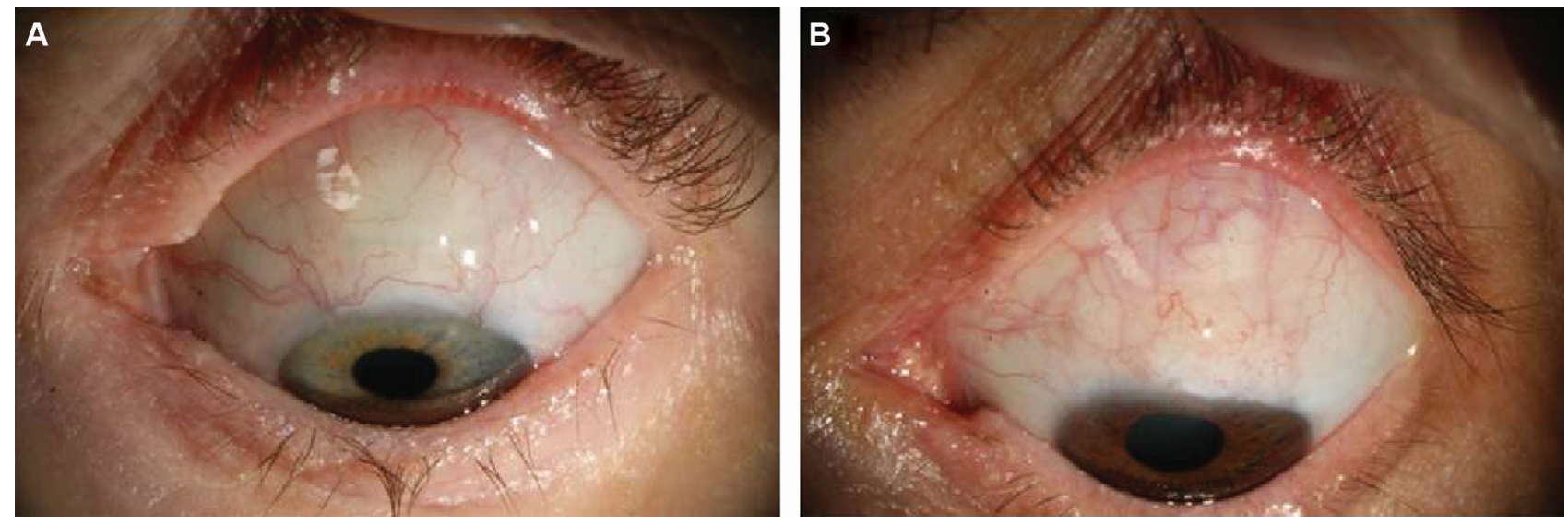

Figure 2 Representative blebs from (A) bevacizumab group and (B) placebo group showing less vascularity in the bevacizumab-treated eye at 6 months postoperatively. Note: Reproduced from Intracameral bevacizumab as an adjunct to trabeculectomy: a I-year prospective, randomised study. Vandewalle E, Abegao Pinto L, Van Bergen T, et al, Vol 98, pages 73-78, Copyright (c) 2014 with permission from BMJ Publishing Group Ltd. ${ }^{75}$

perspectives for the use of anti-VEGF therapy to prevent filtration failure after glaucoma surgery.

\section{Inhibition of placental growth factor}

Importantly, although bevacizumab could improve the surgical outcome by inhibiting angiogenesis and deposition of collagen, and VEGF is known to have proinflammatory properties, neither selective nor nonselective VEGF inhibition could reduce inflammation, another important process in postoperative healing. ${ }^{53,61}$ Our group showed that the upregulated levels of aqueous placental growth factor after administration of bevacizumab might explain why anti-VEGF therapy was not sufficient to reduce the inflammatory response after glaucoma surgery. Indeed, aqueous placental growth factor levels were significantly upregulated in patients with glaucoma compared with control subjects. Moreover, intracameral injection of anti-placental growth factor antibody (5.2 $\mu \mathrm{g}$, ThromboGenics NV, Leuven, Belgium) effectively improved the surgical outcome in a mouse model of trabeculectomy, by increasing the bleb area and survival after surgery compared with an irrelevant antibody control and with the VEGF-R2 antibody. The effect on surgical outcome was associated with a decreased angiogenesis, fibrosis, and importantly, inflammation. Therefore, inhibition of placental growth factor might theoretically be even more effective than inhibition of VEGF, due to the additional effect on inflammation. ${ }^{76}$

\section{Other growth factors, cytokines, and proteinases}

Several other molecules, including growth factors (eg, plateletderived growth factor) cytokines (eg, interleukin-6, interleukin-8, and tumor necrosis factor- $\alpha$ ), and matrix metalloproteinases (eg, MMP-2 and MMP-3) have been reported to be upregulated after glaucoma filtration surgery. ${ }^{77-80}$ Different studies have shown that these factors can stimulate proliferation of Tenon fibroblasts in vitro. ${ }^{81,82}$ Moreover, inhibition of some of these factors reduced growth of Tenon fibroblasts ${ }^{83}$ and improved surgical outcome in a rabbit model of glaucoma. ${ }^{84,85}$ However, none of these inhibitors have reached clinical trials. This can probably be explained by the fact that upregulation of TGF- $\beta 2$ and VEGF in patients with glaucoma correlates strongly with surgical failure, whereas other factors (eg, MMP-1, interleukin-6, and interleukin-8) are associated with surgical success. ${ }^{86}$

\section{Inhibition of ROCK}

Rho kinases (ROCK 1 and 2) are major downstream effectors of Rho-GTPase proteins and mediate a number of important cellular functions associated with cytoskeletal rearrangement, such as cell morphology, motility, adhesion, contraction, and cytokinesis. ${ }^{87}$ It is known that ROCK plays an important role in a number of wound healing processes, ie, inflammation, angiogenesis, and fibrosis. Administration of ROCK inhibitors on lipopolysaccharidestimulated inflammatory cells decreased the activation of NF- $\kappa \beta$ and subsequently blocked the generation of proinflammatory cytokines, such as interleukin-1 $\beta / 6$ and tumor necrosis factor- $\alpha .{ }^{88-90}$ Increased expression of RhoA in endothelial cells also significantly enhanced migration and angiogenic capacity in vitro, which suggests an important role for the Rho/ROCK pathway in these processes. ${ }^{91}$ Furthermore, van Niew-Amerongen et al showed demonstrated that inhibition of the Rho/ROCK pathway 
attenuated VEGF-mediated migration and angiogenesis in vitro. ${ }^{92}$ Importantly, in vitro studies also showed that contractility of Tenon fibroblasts is essential in the transdifferentation into myofibroblasts. Inhibition of the Rho/ROCK pathway by specific kinase inhibitors (Y-27632 [Novartis AG, Basel, Switzerland], HA-1077 [Santen Pharmaceutical Co., Ltd., Osaka, Japan], H-1152 [Calbiochem ${ }^{\circledR}$; Merck KGaA, Darmstadt, Germany], and ML-7 [Merck KGaA]) is known to counteract this contraction by blocking TGF- $\beta$ or lysophospholipid acid-induced activation of Tenon fibroblasts. ${ }^{93,94}$ Secondly, Honjo et al showed that topical treatment with the ROCK inhibitor Y-27632 had profound effects on surgical outcome in a rabbit model of glaucoma surgery. Histological examination revealed that blebs treated with Y-27632 lacked significant collagen deposition compared with vehicle treatment. ${ }^{93}$ As such, ROCK inhibitors could strengthen our armamentarium to improve the effectiveness of filtration surgery, because these inhibitors have the potency to interfere at different levels of the wound healing process.

\section{Future perspectives}

Although bevacizumab has been proven to be effective in reducing wound healing after filtering glaucoma surgery in a prospective clinical trial, mitomycin $\mathrm{C}$ is still the most common antifibrotic agent used during trabeculectomy in routine clinical practice. This study may represent a breakthrough in the quest for novel antifibrotic strategies in filtering surgery; however, some additional questions remain to be answered. The most optimal route of administration of anti-VEGF drugs is still unknown. Nomoto et al showed that, despite lower maximal concentrations of bevacizumab after subconjunctival injection in the rabbit eye, the intraocular half-life was higher after subconjunctival injection as compared with intravitreal injection. ${ }^{95}$ Ambati et al showed that immunoglobulin $\mathrm{G}$ antibodies have a relatively high scleral permeability. ${ }^{96}$ Since bevacizumab is an immunoglobulin G1 antibody, it should penetrate intraocular tissues via the sclera, which might then work as a sustained-release mechanism. Recent studies in a rabbit model of glaucoma surgery showed that postoperative subconjunctival injection of bevacizumab was more effective than intravitreal administration. ${ }^{97}$ It also remains unknown whether bevacizumab could replace antimitotics in clinical practice, or if it should be considered as an adjunctive to antimitotics. Although some small comparative ${ }^{69,70,98}$ and complementary studies ${ }^{99,100}$ have been performed, large randomized clinical trials are still lacking.
A variety of alternative antiscarring strategies (Table 1), such as photodynamic therapy, ${ }^{101-104}$ saratin (Merck KGaA), ${ }^{105,106}$ sonepcizumab (Lpath, Inc., San Diego, CA, USA) ${ }^{107}$ doxycycline (Pfizer Inc.), ${ }^{108}$ pirfenidone (InterMune, Brisbane, CA, USA), ${ }^{109,110}$ tacrolimus (Astellas Pharma Inc., Tokyo, Japan), ${ }^{111}$ and octreotide (Novartis), ${ }^{111}$ have also shown promising results by improving the outcome of surgery in a standard rabbit model. Although many agents have been evaluated in preclinical models for glaucoma filtration surgery, few have been found to be beneficial in large prospective comparative clinical trials and none have replaced mitomycin $\mathrm{C}$ or 5-fluorouracil in clinical practice so far. Therefore, it is necessary to broaden the therapeutic approach, given that treatment with a single agent may lead to drug resistance. Indeed, because of the complexity of the wound healing process, ${ }^{4,5}$ it is possible that targeting one molecule may be insufficient to impede the wound healing process due to the upregulation of other growth factors. It has been suggested that mitomycin $\mathrm{C}$ can upregulate proinflammatory, proangiogenic, and/or profibrotic factors. Therefore, combining mitomycin $\mathrm{C}$ with drugs that block these upregulated profibrotic growth factors may offer promising complementary efficacy and allow a lower dose of mitomycin $\mathrm{C}$ to be used, with fewer side effects.

Finally, wound healing is a relatively slow process involving interaction between the antiscarring agent and the target tissue (Tenon's capsule) for several weeks to months. Therefore, future research should focus on the development of targeted drug delivery systems that improve and/or prolong contact between the target tissues and the antiscarring molecules. A few studies have already been published in which a slow-release formulation of 5-fluorouracil is described. Collagen plugs, ${ }^{112}$ polyesters, ${ }^{113}$ and amniotic membranes ${ }^{114}$ containing the antimitotic agent were shown to induce a prolonged effect on bleb survival in the standard rabbit model. The effect of a sustained-release dexamethasone implant (Ozurdex ${ }^{\circledR}$, Allergan, Irvine, CA, USA) on postoperative wound healing was also investigated in this animal model, and was found to be effective in prolonging bleb survival. However, mitomycin C-treated blebs showed significantly longer survival compared with Ozurdex-treated blebs. ${ }^{115}$

Khalili et al developed a new solid tissue tablet that provides prolonged release of bevacizumab in vitro, and an in vivo study showed substantially prolonged bleb survival compared with mitomycin $\mathrm{C}$ in the rabbit model. ${ }^{116}$ Thus, this antibody tablet has the potential to prolong local antibody release and exert a significant biological effect. These data are 
very promising, but further studies are required. If successful, such improved drug delivery systems might significantly improve the efficacy of known antiscarring molecules and possibly decrease their side effects.

\section{Conclusion}

Failing filtering surgery due to an excessive healing reaction is still a considerable problem in ophthalmology, and contributes to progressive vision loss in patients with glaucoma. Although a number of studies have demonstrated that many antifibrotic agents can reduce postoperative wound healing in the preclinical setting, bevacizumab is the only agent that has been proven to be effective in a prospective randomized clinical trial. Further research should focus on targeting multiple steps of the wound healing process by use of combination therapy and also on new methods of extended drug delivery to improve the efficacy of the known antiscarring agents. Finally, we should be cautious when extrapolating preclinical findings to the management of human disease. Animal models are not precise replicas of human pathology, and the pharmacokinetics and half-lives of the therapeutic agents might differ between animals and human eyes. Therefore, further clinical trials in humans with long-term follow-up and inclusion of comparative controls are required.

\section{Disclosure}

The authors report no conflicts of interest in this work.

\section{References}

1. Burr J, Azuara-Blanco A, Avenell A. Medical versus surgical interventions for open angle glaucoma. Cochrane Database Syst Rev. 2005; 2:CD004399.

2. Hitchings R. Initial treatment for open-angle glaucoma - medical, laser, or surgical? Surgery is the treatment of choice for open-angle glaucoma. Arch Ophthalmol. 1998;116(2):241-242.

3. Addicks EM, Quigley HA, Green WR, Robin AL. Histologic characteristics of filtering blebs in glaucomatous eyes. Arch Ophthalmol. 1983; 101(5):795-798.

4. Lama PJ, Fechtner RD. Antifibrotics and wound healing in glaucoma surgery. Surv Ophthalmol. 2003;48(3):314-346.

5. Georgoulas S, Dahlmann-Noor A, Brocchini S, Khaw PT. Modulation of wound healing during and after glaucoma surgery. Prog Brain Res. 2008; 173:237-254.

6. Skuta GL, Parrish RK, 2nd. Wound healing in glaucoma filtering surgery. Surv Ophthalmol. 1987;32(3):149-170.

7. Miller MH, Joseph NH, Ennis KW, Grierson I, Hitchings RA. An animal model of filtration surgery. Trans Ophthalmol Soc U K. 1985;104 Pt 8: 893-897.

8. Schultz G, Chegini N, Grant M, Khaw P, MacKay S. Effects of growth factors on corneal wound healing. Acta Ophthalmol Suppl. 1992; 202:60-66.

9. Wong J, Wang N, Miller JW, Schuman JS. Modulation of human fibroblast activity by selected angiogenesis inhibitors. Exp Eye Res. 1994;58(4):439-451.

10. Tripathi RC, Parapuram SK, Tripathi BJ, Zhong Y, Chalam KV. Corticosteroids and glaucoma risk. Drugs Aging. 1999;15(6):439-450.
11. Clark AF, Wordinger RJ. The role of steroids in outflow resistance. Exp Eye Res. 2009;88(4):752-759.

12. Johnson DH, Matsumoto Y. Schlemm's canal becomes smaller after successful filtration surgery. Arch Ophthalmol. 2000;118(9): $1251-1256$.

13. Lutjen-Drecoll E, Barany EH. Functional and electron microscopic changes in the trabecular meshwork remaining after trabeculectomy in cynomolgus monkeys. Invest Ophthalmol. 1974;13(7): $511-524$.

14. Thomas R, Jay JL. Raised intraocular pressure with topical steroids after trabeculectomy. Graefes Arch Clin Exp Ophthalmol. 1988; 226(4):337-340.

15. Araujo SV, Spaeth GL, Roth SM, Starita RJ. A ten-year follow-up on a prospective, randomized trial of postoperative corticosteroids after trabeculectomy. Ophthalmology. 1995;102(12):1753-1759.

16. Muecke J, Brian G. Steroid-induced ocular hypertension in the presence of a functioning Molteno seton. Aust N Z J Ophthalmol. 1995; 23(1):67-68.

17. Chang MR, Cheng Q, Lee DA. Basic science and clinical aspects of wound healing in glaucoma filtering surgery. J Ocul Pharmacol Ther. 1998;14(1):75-95.

18. Skuta GL, Beeson CC, Higginbotham EJ, et al. Intraoperative mitomycin versus postoperative 5-fluorouracil in high-risk glaucoma filtering surgery. Ophthalmology. 1992;99(3):438-444.

19. Khaw PT, Sherwood MB, MacKay SL, Rossi MJ, Schultz G. Five-minute treatments with fluorouracil, floxuridine, and mitomycin have longterm effects on human Tenon's capsule fibroblasts. Arch Ophthalmol. 1992;110(8):1150-1154.

20. Gressel MG, Parrish RK, 2nd, Folberg R. 5-fluorouracil and glaucoma filtering surgery: I. An animal model. Ophthalmology. 1984;91(4): 378-383.

21. Shapiro MS, Thoft RA, Friend J, Parrish RK, Gressel MG. 5-Fluorouracil toxicity to the ocular surface epithelium. Invest Ophthalmol Vis Sci. 1985; 26(4):580-583.

22. Smith S, D'Amore PA, Dreyer EB. Comparative toxicity of mitomycin C and 5-fluorouracil in vitro. Am J Ophthalmol. 1994;118(3): 332-337.

23. Megevand GS, Salmon JF, Scholtz RP, Murray AD. The effect of reducing the exposure time of mitomycin $\mathrm{C}$ in glaucoma filtering surgery. Ophthalmology. 1995;102(1):84-90.

24. Schnyder CC, Bernasconi O, Mermoud A, Faggioni R. 2,5 oder 5minütige Applikation von Mitomycin $\mathrm{C}$ bei fistulisierenden Operationen? Eine Vergleichstudie [Comparative study of administration time of mitomycin C in trabeculectomy: 2.5 or 5 minutes?]. Klin Monbl Augenheilkd. 1995;206(5):307-311. German.

25. Thornton I, Xu M, Krueger RR. Comparison of standard ( $0.02 \%)$ and low dose $(0.002 \%)$ mitomycin $\mathrm{C}$ in the prevention of corneal haze following surface ablation for myopia. J Refract Surg. 2008;24(1): S68-S76.

26. Matlach J, Panidou E, Grehn F, Klink T. Large-area versus small-area application of mitomycin C during trabeculectomy. Eur J Ophthalmol. 2013;23(5):670-677.

27. Onol M, Aktas Z, Hasanreisoglu B. Enhancement of the success rate in trabeculectomy: large-area mitomycin-C application. Clin Experiment Ophthalmol. 2008;36(4):316-322.

28. Khaw PT, Chang L, Wong TT, Mead A, Daniels JT, Cordeiro MF. Modulation of wound healing after glaucoma surgery. Curr Opin Ophthalmol. 2001;12(2):143-148.

29. Cordeiro MF, Constable PH, Alexander RA, Bhattacharya SS, Khaw PT. Effect of varying the mitomycin-C treatment area in glaucoma filtration surgery in the rabbit. Invest Ophthalmol Vis Sci. 1997;38(8):1639-1646.

30. Khaw PT, Doyle JW, Sherwood MB, Grierson I, Schultz G, McGorray S. Prolonged localized tissue effects from 5-minute exposures to fluorouracil and mitomycin C. Arch Ophthalmol. 1993; 111(2):263-267. 
31. Khaw PT, Sherwood MB, Doyle JW, et al. Intraoperative and postoperative treatment with 5-fluorouracil and mitomycin-C: long term effects in vivo on subconjunctival and scleral fibroblasts. Int Ophthalmol. 1992;16(4-5):381-385.

32. Seong GJ, Park C, Kim CY, et al. Mitomycin-C induces the apoptosis of human Tenon's capsule fibroblast by activation of c-Jun $\mathrm{N}$-terminal kinase 1 and caspase-3 protease. Invest Ophthalmol Vis Sci. 2005;46(10):3545-3552.

33. Soltau JB, Rothman RF, Budenz DL, et al. Risk factors for glaucoma filtering bleb infections. Arch Ophthalmol. 2000;118(3): 338-342.

34. Sisto D, Vetrugno M, Trabucco T, Cantatore F, Ruggeri G, Sborgia C. The role of antimetabolites in filtration surgery for neovascular glaucoma: intermediate-term follow-up. Acta Ophthalmol Scand. 2007;85(3):267-271.

35. Greenfield DS, Liebmann JM, Jee J, Ritch R. Late-onset bleb leaks after glaucoma filtering surgery. Arch Ophthalmol. 1998;116(4):443-447.

36. Higginbotham EJ, Stevens RK, Musch DC, et al. Bleb-related endophthalmitis after trabeculectomy with mitomycin C. Ophthalmology. 1996;103(4):650-656.

37. Karalekas DHA, Rosenberg L, Ruderman J, Krupin T. Effects of human glaucomatous and non-glaucomatous aqueous humor on fibroblast proliferation in vitro. Invest Ophthalmol Vis Sci. 1994;35(4):1898.

38. Tripathi RC, Li J, Chan WF, Tripathi BJ. Aqueous humor in glaucomatous eyes contains an increased level of TGF-beta 2. Exp Eye Res. 1994;59(6):723-727.

39. Cordeiro MF, Bhattacharya SS, Schultz GS, Khaw PT. TGF-beta1, -beta2, and -beta3 in vitro: biphasic effects on Tenon's fibroblast contraction, proliferation, and migration. Invest Ophthalmol Vis Sci. 2000;41(3):756-763.

40. Cordeiro MF, Gay JA, Khaw PT. Human anti-transforming growth factor-beta2 antibody: a new glaucoma anti-scarring agent. Invest Ophthalmol Vis Sci. 1999;40(10):2225-2234.

41. Khaw P, Grehn F, Hollo G, et al. A phase III study of subconjunctival human anti-transforming growth factor beta(2) monoclonal antibody (CAT-152) to prevent scarring after first-time trabeculectomy. Ophthalmology. 2007;114(10):1822-1830.

42. Grisanti S, Szurman P, Warga M, et al. Decorin modulates wound healing in experimental glaucoma filtration surgery: a pilot study. Invest Ophthalmol Vis Sci. 2005;46(1):191-196.

43. Mietz H, Krieglstein GK. Suramin to enhance glaucoma filtering procedures: a clinical comparison with mitomycin. Ophthalmic Surg Lasers. 2001;32(5):358-369.

44. Mietz H, Chevez-Barrios P, Feldman RM, Lieberman MW. Suramin inhibits wound healing following filtering procedures for glaucoma. Br J Ophthalmol. 1998;82(7):816-820.

45. Spitzer MS, Sat M, Schramm C, et al. Biocompatibility and antifibrotic effect of UV-cross-linked hyaluronate as a release-system for tranilast after trabeculectomy in a rabbit model - a pilot study. Curr Eye Res. 2012; 37(6):463-470.

46. Oshima T, Kurosaka D, Kato K, et al. Tranilast inhibits cell proliferation and collagen synthesis by rabbit corneal and Tenon's capsule fibroblasts. Curr Eye Res. 2000;20(4):283-286.

47. Chihara E, Dong J, Ochiai H, Hamada S. Effects of tranilast on filtering blebs: a pilot study. J Glaucoma. 2002;11(2):127-133.

48. Meyer-Ter-Vehn T, Katzenberger B, Han H, Grehn F, Schlunck G. Lovastatin inhibits TGF-beta-induced myofibroblast transdifferentiation in human Tenon fibroblasts. Invest Ophthalmol Vis Sci. 2008; 49(9):3955-3960.

49. Xiao YQ, Liu K, Shen JF, Xu GT, Ye W. SB-431542 inhibition of scar formation after filtration surgery and its potential mechanism. Invest Ophthalmol Vis Sci. 2009;50(4):1698-1706.

50. Sapitro J, Dunmire JJ, Scott SE, et al. Suppression of transforming growth factor-beta effects in rabbit subconjunctival fibroblasts by activin receptor-like kinase 5 inhibitor. Mol Vis. 2010;16: 1880-1892.
51. Li N, Cui J, Duan X, Chen H, Fan F. Suppression of type I collagen expression by miR-29b via PI3K, Akt, and Sp1 pathway in human Tenon's fibroblasts. Invest Ophthalmol Vis Sci. 2012;53(3):1670-1678.

52. Bao P, Kodra A, Tomic-Canic M, Golinko MS, Ehrlich HP, Brem H. The role of vascular endothelial growth factor in wound healing. J Surg Res. 2009;153(2):347-358.

53. Li Z, Van Bergen $\mathrm{T}$, Van de Veire $\mathrm{S}$, et al. Inhibition of vascular endothelial growth factor reduces scar formation after glaucoma filtration surgery. Invest Ophthalmol Vis Sci. 2009;50(11):5217-5225.

54. Hu DN, Ritch R, Liebmann J, Liu Y, Cheng B, Hu MS. Vascular endothelial growth factor is increased in aqueous humor of glaucomatous eyes. J Glaucoma. 2002;11(5):406-410.

55. Tripathi RC, Li J, Tripathi BJ, Chalam KV, Adamis AP. Increased level of vascular endothelial growth factor in aqueous humor of patients with neovascular glaucoma. Ophthalmology. 1998;105(2):232-237.

56. Beddy D, Watson RW, Fitzpatrick JM, O'Connell PR. Increased vascular endothelial growth factor production in fibroblasts isolated from strictures in patients with Crohn's disease. Br J Surg. 2004;91(1):72-77.

57. Nissen NN, Polverini PJ, Koch AE, Volin MV, Gamelli RL, DiPietro LA. Vascular endothelial growth factor mediates angiogenic activity during the proliferative phase of wound healing. Am J Pathol. 1998;152(6):1445-1452.

58. Wilgus TA, Ferreira AM, Oberyszyn TM, Bergdall VK, Dipietro LA. Regulation of scar formation by vascular endothelial growth factor. Lab Invest. 2008;88(6):579-590.

59. Memarzadeh F, Varma R, Lin LT, et al. Postoperative use of bevacizumab as an antifibrotic agent in glaucoma filtration surgery in the rabbit. Invest Ophthalmol Vis Sci. 2009;50(7):3233-3237.

60. How A, Chua JL, Charlton A, et al. Combined treatment with bevacizumab and 5-fluorouracil attenuates the postoperative scarring response after experimental glaucoma filtration surgery. Invest Ophthalmol Vis Sci. 2010;51(2):928-932.

61. Van Bergen T, Vandewalle E, Van de Veire S, et al. The role of different VEGF isoforms in scar formation after glaucoma filtration surgery. Exp Eye Res. 2011;93(5):689-699.

62. Kahook MY, Schuman JS, Noecker RJ. Needle bleb revision of encapsulated filtering bleb with bevacizumab. Ophthalmic Surg Lasers Imaging. 2006;37(2):148-150.

63. Coote MA, Ruddle JB, Qin Q, Crowston JG. Vascular changes after intra-bleb injection of bevacizumab. J Glaucoma. 2008;17(7):517-518.

64. Zarnowski T, Tulidowicz-Bielak M. Topical bevacizumab is efficacious in the early bleb failure after trabeculectomy. Acta Ophthalmol. 2011;89(7):e605-e606.

65. Biteli LG, Prata TS. Subconjunctival bevacizumab as an adjuvant in first-time filtration surgery for patients with primary glaucomas. Int Ophthalmol. 2013;33(6):741-746.

66. Klos-Rola J, Tulidowicz-Bielak M, Zarnowski T. Effects of topical bevacizumab application on early bleb failure after trabeculectomy: observational case series. Clin Ophthalmol. 2013;7:1929-1935.

67. Akkan JU, Cilsim S. Role of subconjunctival bevacizumab as an adjuvant to primary trabeculectomy: a prospective randomized comparative 1-year follow-up study. J Glancoma. May 8, 2013. [Epub ahead of print].

68. Grewal DS, Jain R, Kumar H, Grewal SP. Evaluation of subconjunctival bevacizumab as an adjunct to trabeculectomy a pilot study. Ophthalmology. 2008;115(12):2141-2145.e2142.

69. Nilforushan N, Yadgari M, Kish SK, Nassiri N. Subconjunctival bevacizumab versus mitomycin $\mathrm{C}$ adjunctive to trabeculectomy. Am J Ophthalmol. 2012;153(2):352-357.e351.

70. Sengupta S, Venkatesh R, Ravindran RD. Safety and efficacy of using off-label bevacizumab versus mitomycin $\mathrm{C}$ to prevent bleb failure in a single-site phacotrabeculectomy by a randomized controlled clinical trial. J Glaucoma. 2012;21(7):450-459.

71. Sedghipour MR, Mostafaei A, Taghavi Y. Low-dose subconjunctival bevacizumab to augment trabeculectomy for glaucoma. Clin Ophthalmol. 2011;5:797-800. 
72. Chua BE, Nguyen DQ, Qin Q, et al. Bleb vascularity following posttrabeculectomy subconjunctival bevacizumab: a pilot study. Clin Experiment Ophthalmol. 2012;40(8):773-779.

73. Jurkowska-Dudzinska J, Kosior-Jarecka E, Zarnowski T. Comparison of the use of 5-fluorouracil and bevacizumab in primary trabeculectomy: results at 1 year. Clin Experiment Ophthalmol. 2012;40(4): e135-e142.

74. Suh W, Kee C. The effect of bevacizumab on the outcome of trabeculectomy with 5-fluorouracil. JOcul Pharmacol Ther. 2013;29(7): 646-651.

75. Vandewalle E, Abegao Pinto L, Van Bergen T, et al. Intracameral bevacizumab as an adjunct to trabeculectomy: a 1-year prospective, randomised study. Br J Ophthalmol. 2014;98(1):73-78.

76. Van Bergen T, Jonckx B, Hollanders K, et al. Inhibition of placental growth factor improves surgical outcome of glaucoma surgery. J Cell Mol Med. 2013;17(12):1632-1643.

77. Inoue $\mathrm{T}$, Kawaji $\mathrm{T}$, Inatani M, Kameda $\mathrm{T}$, Yoshimura N, Tanihara H. Simultaneous increases in multiple proinflammatory cytokines in the aqueous humor in pseudophakic glaucomatous eyes. J Cataract Refract Surg. 2012;38(8):1389-1397.

78. Takai Y, Tanito M, Ohira A. Multiplex cytokine analysis of aqueous humor in eyes with primary open-angle glaucoma, exfoliation glaucoma, and cataract. Invest Ophthalmol Vis Sci. 2012;53(1):241-247.

79. Kuchtey J, Rezaei KA, Jaru-Ampornpan P, Sternberg P Jr, Kuchtey RW. Multiplex cytokine analysis reveals elevated concentration of interleukin-8 in glaucomatous aqueous humor. Invest Ophthalmol Vis Sci. 2010;51(12):6441-6447.

80. Schlotzer-Schrehardt U, Lommatzsch J, Kuchle M, Konstas AG, Naumann GO. Matrix metalloproteinases and their inhibitors in aqueous humor of patients with pseudoexfoliation syndrome/glaucoma and primary open-angle glaucoma. Invest Ophthalmol Vis Sci. 2003; 44(3):1117-1125.

81. Knorr M, Volker M, Denk PO, Wunderlich K, Thiel HJ. Proliferative response of cultured human Tenon's capsule fibroblasts to plateletderived growth factor isoforms. Graefes Arch Clin Exp Ophthalmol. 1997;235(10):667-671.

82. Cunliffe IA, Richardson PS, Rees RC, Rennie IG. Effect of TNF, IL-1, and IL- 6 on the proliferation of human Tenon's capsule fibroblasts in tissue culture. Br J Ophthalmol. 1995;79(6):590-595.

83. Salas-Prato M, Assalian A, Mehdi AZ, Duperre J, Thompson P, Brazeau P. Inhibition by rapamycin of PDGF- and bFGF-induced human tenon fibroblast proliferation in vitro. J Glaucoma. 1996;5(1):54-59.

84. Wong TT, Mead AL, Khaw PT. Matrix metalloproteinase inhibition modulates postoperative scarring after experimental glaucoma filtration surgery. Invest Ophthalmol Vis Sci. 2003;44(3):1097-1103.

85. Martin-Martin B, Tovell V, Dahlmann-Noor AH, Khaw PT, Bailly M. The effect of MMP inhibitor GM6001 on early fibroblast-mediated collagen matrix contraction is correlated to a decrease in cell protrusive activity. Eur J Cell Biol. 2011;90(1):26-36.

86. Rodriguez-Agirretxe I, Garcia I, Soria J, Acera A, Suarez-Cortes TM. Prognosis of glaucoma surgery failure by customized gene expression PCR-array. Invest Ophthalmol Vis Sci. 2012;53:ARVO E-Abstract 2514.

87. Liao JK, Seto M, Noma K. Rho kinase (ROCK) inhibitors. J Cardiovasc Pharmacol. 2007;50(1):17-24.

88. Doe C, Bentley R, Behm DJ, et al. Novel Rho kinase inhibitors with anti-inflammatory and vasodilatory activities. J Pharmacol Exp Ther. 2007;320(1):89-98.

89. He Y, Xu H, Liang L, et al. Antiinflammatory effect of Rho kinase blockade via inhibition of NF-kappaB activation in rheumatoid arthritis. Arthritis Rheum. 2008;58(11):3366-3376.

90. Okamoto H, Yoshio $\mathrm{T}$, Kaneko H, Yamanaka H. Inhibition of NF-kappaB signaling by fasudil as a potential therapeutic strategy for rheumatoid arthritis. Arthritis Rheum. 2010;62(1):82-92.

91. Zhao L, Xu G, Zhou J, et al. The effect of RhoA on human umbilical vein endothelial cell migration and angiogenesis in vitro. Oncol Rep. 2006;15(5):1147-1152.
92. van Nieuw Amerongen GP, Koolwijk P, Versteilen A, van Hinsbergh VW. Involvement of RhoA/Rho kinase signaling in VEGF-induced endothelial cell migration and angiogenesis in vitro. Arterioscler Thromb Vasc Biol. 2003;23(2):211-217.

93. Honjo M, Tanihara H, Kameda T, Kawaji T, Yoshimura N, Araie M. Potential role of Rho-associated protein kinase inhibitor Y-27632 in glaucoma filtration surgery. Invest Ophthalmol Vis Sci. 2007; 48(12):5549-5557.

94. Meyer-ter-Vehn T, Sieprath S, Katzenberger B, Gebhardt S, Grehn F, Schlunck G. Contractility as a prerequisite for TGF-beta-induced myofibroblast transdifferentiation in human Tenon fibroblasts. Invest Ophthalmol Vis Sci. 2006;47(11):4895-4904.

95. Nomoto H, Shiraga F, Kuno N, et al. Pharmacokinetics of bevacizumab after topical, subconjunctival, and intravitreal administration in rabbits. Invest Ophthalmol Vis Sci. 2009;50(10):4807-4813.

96. Ambati J, Gragoudas ES, Miller JW, et al. Transscleral delivery of bioactive protein to the choroid and retina. Invest Ophthalmol Vis Sci. 2000;41(5):1186-1191.

97. Ozgonul C, Mumcuoglu T, Gunal A. The effect of bevacizumab on wound healing modulation in an experimental trabeculectomy model. Curr Eye Res. November 11, 2013. [Epub ahead of print].

98. Anand N, Bong C. Deep sclerectomy with bevacizumab and mitomycin C: a comparative study. J Glaucoma. February 19, 2013. [Epub ahead of print].

99. Kahook MY. Bleb morphology and vascularity after trabeculectomy with intravitreal ranibizumab: a pilot study. Am J Ophthalmol. 2010;150(3):399-403.e391.

100. Freiberg FJ, Matlach J, Grehn F, Karl S, Klink T. Postoperative subconjunctival bevacizumab injection as an adjunct to 5-fluorouracil in the management of scarring after trabeculectomy. Clin Ophthalmol. 2013;7:1211-1217.

101. Chen HY, Ge J, Guo Y, Jin CJ, Lan YQ, Lin MK. [The inhibition effect of photodynamic on human Tenon capsule fibroblast cells]. Zhonghua Yan Ke Za Zhi. 2003;39(3):160-162. Chinese.

102. Jordan JF, Diestelhorst M, Grisanti S, Krieglstein GK. Photodynamic modulation of wound healing in glaucoma filtration surgery. $\mathrm{Br} \mathrm{J}$ Ophthalmol. 2003;87(7):870-875.

103. Diestelhorst M, Grisanti S. Photodynamic therapy to control fibrosis in human glaucomatous eyes after trabeculectomy: a clinical pilot study. Arch Ophthalmol. 2002;120(2):130-134.

104. Saeed AM. Comparative study between trabeculectomy with photodynamic therapy (BCECF-AM) and trabeculectomy with antimetabolite (MMC) in the treatment of primary open angle glaucoma. Clin Ophthalmol. 2012;6:1651-1664.

105. Min J, Lukowski ZL, Levine MA, et al. Prevention of ocular scarring post glaucoma filtration surgery using the inflammatory cell and platelet binding modulator saratin in a rabbit model. PLoS One. 2012;7(4):e35627.

106. Min J, Lukowski ZL, Levine MA, et al. Comparison of single versus multiple injections of the protein saratin for prolonging bleb survival in a rabbit model. Invest Ophthalmol Vis Sci. 2012;53(12): 7625-7630.

107. Lukowski ZL, Min J, Beattie AR, et al. Prevention of ocular scarring after glaucoma filtering surgery using the monoclonal antibody LT1009 (sonepcizumab) in a rabbit model. J Glaucoma. 2013;22(2):145-151.

108. Sen E, Balikoglu-Yilmaz M, Bozdag-Pehlivan S, et al. Effect of doxycycline on postoperative scarring after trabeculectomy in an experimental rabbit model. J Ocul Pharmacol Ther. 2010;26(5): 399-406.

109. Lin X, Yu M, Wu K, Yuan H, Zhong H. Effects of pirfenidone on proliferation, migration, and collagen contraction of human Tenon's fibroblasts in vitro. Invest Ophthalmol Vis Sci. 2009;50(8): 3763-3770.

110. Zhong H, Sun G, Lin X, Wu K, Yu M. Evaluation of pirfenidone as a new postoperative antiscarring agent in experimental glaucoma surgery. Invest Ophthalmol Vis Sci. 2011;52(6):3136-3142. 
111. Arslan S, Aydemir O, Guler M, Dagli AF. Modulation of postoperative scarring with tacrolimus and octreotide in experimental glaucoma filtration surgery. Curr Eye Res. 2012;37(3):228-233.

112. Jacob JT, Lacour OJ, Burgoyne CF. Slow release of the antimetabolite 5-fluorouracil (5-FU) from modified Baerveldt glaucoma drains to prolong drain function. Biomaterials. 2001;22(24):3329-3335.

113. Polak MB, Valamanesh F, Felt O, et al. Controlled delivery of 5-chlorouracil using poly (ortho esters) in filtering surgery for glaucoma. Invest Ophthalmol Vis Sci. 2008;49(7):2993-3003.

114. Li W, Chen WJ, Liu W, Liang L, Zhang MC. Homemade lyophilized cross linking amniotic sustained-release drug membrane with antiscarring role after filtering surgery in rabbit eyes. Int $J$ Ophthalmol. 2012;5(5):555-561.
115. SooHoo JR, Seibold LK, Laing AE, Kahook MY. Bleb morphology and histology in a rabbit model of glaucoma filtration surgery using Ozurdex $^{\circledR}$ ) or mitomycin-C. Mol Vis. 2012;18:714-719.

116. Khalili A, Rayapureddi S, Paul DJ, et al. A novel slow release solid bevacizumab tissue tablet prevents scarring following experimental glaucoma filtration surgery (GFS). Abstract 1645 presented at the Research in Vision and Ophthalmology Annual Meeting, May 1-5, 2011, Fort Lauderdale, FL, USA.
Clinical Ophthalmology

\section{Publish your work in this journal}

Clinical Ophthalmology is an international, peer-reviewed journal covering all subspecialties within ophthalmology. Key topics include: Optometry; Visual science; Pharmacology and drug therapy in eye diseases; Basic Sciences; Primary and Secondary eye care; Patien Safety and Quality of Care Improvements. This journal is indexed on

Submit your manuscript here: http://www.dovepress.com/clinical-ophthalmology-journal

\section{Dovepress}

PubMed Central and CAS, and is the official journal of The Society of Clinical Ophthalmology (SCO). The manuscript management system is completely online and includes a very quick and fair peer-review system, which is all easy to use. Visit http://www.dovepress.com/ testimonials.php to read real quotes from published authors. 